\title{
Inflectional complexity and experience affect plural processing in younger and older readers of Dutch and German
}

\author{
Jana Reifegerste, Antje S. Meyer \& Pienie Zwitserlood
}

To cite this article: Jana Reifegerste, Antje S. Meyer \& Pienie Zwitserlood (2017) Inflectional complexity and experience affect plural processing in younger and older readers of Dutch and German, Language, Cognition and Neuroscience, 32:4, 471-487, DOI: 10.1080/23273798.2016.1247213

To link to this article: http://dx.doi.org/10.1080/23273798.2016.1247213

View supplementary material $\asymp$

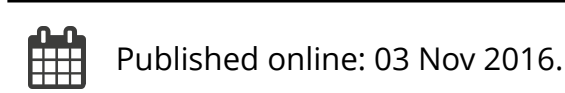

16 Submit your article to this journal 주

Џ Article views: 95

Q View related articles $\sqsubset$

View Crossmark data ¿` 


\title{
Inflectional complexity and experience affect plural processing in younger and older readers of Dutch and German
}

\author{
Jana Reifegerste ${ }^{a}$, Antje S. Meyer ${ }^{b, c}$ and Pienie Zwitserlood ${ }^{d}$

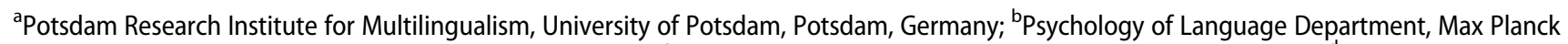 \\ Institute for Psycholinguistics, Nijmegen, The Netherlands; 'Radboud University Nijmegen, Nijmegen, The Netherlands; ${ }^{\mathrm{d}}$ Institute for \\ Psychology, Department of Psychology and Otto Creutzfeldt Center for Cognitive and Behavioral Neuroscience, Westfälische \\ Wilhelms-Universität Münster, Münster, Germany
}

\begin{abstract}
According to dual-route models of morphological processing, regular inflections can be retrieved as whole-word forms or decomposed into morphemes. Baayen, Dijkstra, and Schreuder [(1997). Singulars and plurals in Dutch: Evidence for a parallel dual-route model. Journal of Memory and Language, 37, 94-117. doi:10.1006/jmla.1997.2509] proposed a dual-route model in which singular-dominant plurals ("brides") are decomposed, while plural-dominant plurals ("peas") are accessed as whole-word units. We report two lexical-decision experiments investigating how plural processing is influenced by participants' age and morphological complexity of the language (German/Dutch). For all Dutch participants and older German participants, we replicated the interaction between number and dominance reported by Baayen and colleagues. Younger German participants showed a main effect of number, indicating decomposition of all plurals. Access to stored forms seems to depend on morphological richness and experience with word forms. The data pattern fits neither full-decomposition nor full-storage models, but is compatible with dual-route models.
\end{abstract}

\section{ARTICLE HISTORY}

Received 3 January 2016

Accepted 2 October 2016

\section{KEYWORDS}

Morphological processing; morphological complexity; ageing; lexical decision; plural processing
Most of the world's languages have formal means to express quantity or number, with singular and plural as a minimal distinction. There are many ways to express plural on nouns, for example by reduplication - as in Malay buku-buku ("books") or by adding an inflectional suffix - as in most Eurasian and African languages. Book/books (English), boek/boeken (Dutch), livre/livres (French), Buch/Bücher (German), sefer/sfarim (Hebrew), and kitabu/vitabu (Swahili) are examples from languages that use morphological means to express plurality.

Inflection is a morphological process that can be implemented in different ways in the minds of listeners and speakers. Theories of morphological processing to be detailed below - diverge with respect to these implementations, and one crucial factor concerns inflectional regularity. In English, the regular way to form a plural is by adding an $-s$ (with the spoken variants $/ \mathrm{s} /$, /z/, /əs/, /əz/). Thus, oxen and sheep, for example, are clearly irregular. Regular plurals may be generated and parsed by combining stems and affixes and by decomposing words into these components, respectively. English irregular plurals have to be stored in memory.

There are a number of factors that may influence how language users process plural in their language. The first concerns the morphological richness of their language, in particular with respect to inflection. While some languages have few exceptions to regularity, others have many ways in which plural is morphologically implemented. Another factor is the experience language users have with plural and singular words in their language. It is generally assumed that experience is reflected in word frequency - the frequency of occurrence of a particular word in the language (Alegre \& Gordon, 1999; Stemberger \& MacWhinney, 1986). Word frequency differs not only between words such as bake and bask, but can also differ for singular and plural forms of the same word (Baayen, Dijkstra, \& Schreuder, 1997). Some concepts or objects are most often referred to in their plural form (e.g. eyes, guts), others occur more often in their singular form (e.g. nose, parlour). This is labelled "dominance" and was manipulated in our experiments. Individual differences constitute another aspect of experience: a florist will have used and heard the word roses far more often than a butcher. Age determines experience in a similar manner: a 70-year-old person has heard or read words more often than a 20year-old. All three above factors were assessed in our study on the visual processing of plural inflection: (1) 
the morphological complexity of the language with respect to plural inflection by comparing German and Dutch, (2) the singular or plural dominance of a word form in the language, and (3) the amount of experience of language users with word forms, due to their age.

These factors may well determine how plural inflection is processed, and models of morphological processing, laid out in the next section, make different predictions with respect to their impact. After a summary of these models, we discuss differences with respect to plural inflection between German and Dutch, the two languages tested, and between older and younger people - as a function of their experience with words across the life span. Finally, we provide details about plural vs. singular dominance and our manipulation of word-form frequency, and derive predictions from different models about the impact of the variables manipulated in our experiments.

\section{Models of morphological processing}

Most theories of the processing of morphologically complex words were developed on the basis of studies of reading, to a lesser extent on spoken-word processing and data from persons with language impairments, and fewer still on evidence from speech production studies. The models differ in two crucial aspects. The first aspect concerns the processing of morphologically complex words: are they parsed/decomposed, or are they stored in and retrieved from lexical memory as whole units? The second aspect is whether complex words are handled by a single or by a dual system (see Smolka, Zwitserlood, \& Rösler, 2007 for this distinction).

Prime examples of single-process/single-system models are connectionist network models, in which a single associative memory system computes meaning representations from orthographic representations. Morphological regularities are a by-product of these form-tomeaning mappings (Bybee, 1995; Plaut \& Gonnerman, 2000; Rueckl, Mikolinski, Raveh, Miner, \& Mars, 1997; Rumelhart \& McClelland, 1986; Seidenberg \& Gonnerman, 2000; Smith, 1995; Westermann \& Plunkett, 2007). In such models, morphologically complex and simple words are processed in the same way, by one system and one process. In other single-system models several processes are at work at different stages. Full-parsing models assume that complex forms with detectable affixes are first parsed into separate stem and affix units before whole-word representations can be accessed in a second recombination step (Taft, 1979, 2004; Taft \& Forster, 1975). The reverse sequence is assumed by full-listing models, where lexical access to complex and simple words involves whole-word units.
In a second step, the constituent morphemes of complex words can be retrieved (Giraudo \& Grainger, 2000, 2001), though some full-listing models use this step only as a back-up procedure (Butterworth, 1983).

Dual-route models have both processes, parsing and full-form access, running in parallel. While some complex words are parsed, others are accessed via their stored form in the lexicon (Chialant \& Caramazza, 1995; Clahsen, 1999; Frost, Forster, \& Deutsch, 1997; Marslen-Wilson, Tyler, Waksler, \& Older, 1994; Pinker, 1999; Schreuder \& Baayen, 1995). Models differ as to whether parsing and retrieval are incorporated in a single system (so-called dual-route race models: Frost et al., 1997; Schreuder \& Baayen, 1995), or in two distinct systems (Brovetto \& Ullman, 2005; Clahsen, 1999; Pinker, 1999; Pinker \& Ullman, 2002; Prasada \& Pinker, 1993; Ullman, 2001; Veríssimo \& Clahsen, 2009). Importantly, dual-route models differ in the factors that are assumed to determine access via one or the other route. Such factors are affix type (Colé, Beauvillain, \& Segui, 1989; Cutler, Hawkins, \& Gilligan, 1985; MarslenWilson et al., 1994; Taft, 1994), affix productivity and homonymy (Bertram, Laine, \& Karvinen, 1999; Bertram, Schreuder, \& Baayen, 2000), and the transparency of the semantic relation between a complex word and its parts (e.g. apartment vs. agreement; cf. Feldman \& Soltano, 1999; Marslen-Wilson et al., 1994; but see Andrews \& Lo, 2013; Lüttmann, Zwitserlood, \& Bölte, 2011; Roelofs \& Baayen, 2002 for diverging findings). Two important factors, also addressed in our study, concern regularity (laughed and streets are parsed, wept and oxen are stored; Clahsen, 1999; Prasada \& Pinker, 1993), and word frequency: frequent complex words may be accessed more quickly via direct access than via decomposition (Burani \& Laudanna, 1992; Chialant \& Caramazza, 1995; Laudanna \& Burani, 1995).

For a long time, work on morphological processing has revolved around the "English past-tense debate", but more recent studies have addressed other types of word-formation processes (e.g. derivations, compounds) and languages besides English. So far, systematic differences between (Indo-European) languages and potential influences thereof on morphological processing have received relatively little attention (see New, Brysbaert, Segui, Ferrand, \& Rastle, 2004).

\section{Morphological complexity of the language}

As stated above, languages differ with respect to the ways in which plural inflection is implemented. Although German and Dutch are closely related, they differ in two ways that are relevant for plural processing. Dutch is less morphologically rich than German; it has two genders 
and no case marking. Dutch has two plural affixes (-en, and $-s$ ) to inflect nouns for number (except for about 10 words that take -eren as plural suffix). Which of the two affixes is used is largely predictable from phonology (Baayen, Schreuder, de Jong, \& Krott, 2002; Keuleers et al., 2007; Van Wijk, 2002). German is morphologically more complex than Dutch. It has three genders, inflects nouns for case (four cases in total) and number, with agreement marked on adjectives, determiners, and pronouns. German has no less than five ${ }^{1}$ different plural affixes: $-\varnothing,-(e) n,-e,-e r$, and $-s$. Some of these allow for ablauting through fronting of the stressed vowel in the stem. Linguists have attempted to determine patterns that predict the plural form of a German noun from its phonology, grammatical gender, or semantics, but the list of exceptions to such rules is usually quite long (Köpcke, 1988; Mugdan, 1977). The only rule without exception is that feminine nouns ending in [ə] take $-n$ as their plural affix. By and large, it seems that the type of plural a word takes is arbitrary. Table 1 provides an overview of all plural affixes.

The question addressed here is how the richness of the plural system influences the storage or computation of plural forms. Full-decomposition models predict parsing of all forms that are suffixed and thus detectably complex. Thus, these models predict no differences between the two languages. Dual-route two-system theories predict parsing for regular and storage for irregular forms for each language. For Dutch, $-s$ plural has been suggested as default - a concept based on criteria formulated by Marcus, Brinkmann, Clahsen, Wiese, and Pinker (1995). However, -s plural is infrequent in Dutch, and primarily used with loan words and names. Importantly, more recent research provided ample evidence that, in fact, both plural forms of Dutch should be considered regular (Baayen, Dijkstra, \& Schreuder, 1997; Baayen et al., 2002; Keuleers et al., 2007; Van Wijk, 2002): clippings, nonce words, acronyms, onomatopoeic terms, proper names, and unassimilated borrowings may take -s or -en as the plural affix, depending on the phonological environment (particularly with regard to stress and sonority) created by the singular form. For instance,

Table 1. German plural affixes.

\begin{tabular}{lllll}
\hline Type & \multicolumn{1}{c}{ Size } & \multicolumn{1}{c}{ Ablaut } & \multicolumn{1}{c}{ Example } & \multicolumn{1}{c}{ Gloss } \\
\hline$-\varnothing$ & - & Yes, not predictable & $\begin{array}{l}\text { Krater } \\
\text { Vater } \rightarrow \text { Väter } \\
\text { Huhn } \rightarrow \text { Hühner }\end{array}$ & $\begin{array}{l}\text { "crater(s)" } \\
\text { "fathers" }\end{array}$ \\
"chickens" & & \\
$-e r$ & $2-8 \%$ & $\begin{array}{l}\text { Yes, always for back } \\
\text { vowels }\end{array}$ & $\begin{array}{l}\text { Zebra } \rightarrow \text { Zebras } \\
\text { No }\end{array}$ & "zebras" \\
-5 & $2-8 \%$ & "cows" \\
$-e$ & $22-33 \%$ & Yes, not predictable & $\begin{array}{l}\text { Kuh } \rightarrow \text { Kühe } \\
\text { Hund } \rightarrow \text { Hunde }\end{array}$ & "dogs" \\
& & & Katze $\rightarrow$ Katzen & "cats" \\
\hline
\end{tabular}

Source: Clahsen (1999).

Note: Size is the estimated percentage of words within a paradigm. when participants in a study by Snow, Smith, and Hoefnagel-Höhle (1980) were asked to produce the plural of nonce words (e.g. flik, hinden), they used the phonologically appropriate affix (flikken, hindens). Pinker (1999) explains that, "Dutch has two plurals that pass our stringent tests for regularity, $-s$ and -en [...] Within their fiefdoms each applies as the default" (p. 231). For Dutch, fullparsing models would thus predict decomposition of all plural forms and no effects of the frequency of individual plural word forms.

The situation in German is less clear. Citing developmental (Clahsen, Marcus, \& Bartke, 1993; Clahsen, Rothweiler, Woest, \& Marcus, 1992), behavioural (lexical decision: Clahsen, Eisenbeiss, \& Sonnenstuhl-Henning, 1997; cross-modal priming: Sonnenstuhl, Eisenbeiss, \& Clahsen, 1999), and neuroimaging studies (Beretta et al., 2003; Weyerts, Penke, Dohrn, Clahsen, \& Münte, 1997), Clahsen and colleagues proposed that the -s plural, though rare, qualifies as the only default form in German (Clahsen, 1999; Marcus et al., 1995). Sonnenstuhl et al. (1999), for example, conducted a cross-modal priming experiment and compared priming patters for -er and $-s$ plurals priming their respective singular forms. The authors found partial priming for -er plural forms and full priming for $-s$ plural forms, which was taken as evidence that the former are fully stored forms, while the latter are computed through affixation. Further, $-s$ is highly productive: proper names (even those homophonous with existing nouns, e.g. Bach), clippings, nonce words, loan words, and acronyms usually take on the $-s$ affix.

Under the assumption that $-s$ constitutes the default plural morpheme, parsing would be predicted for $-\mathrm{s}$ plurals and storage for all other forms. Finally, in dualroute race models, frequency (and possibly affix type and productivity) would determine whether a plural form is processed via parsing or via direct access to lexical memory. Detailed predictions from each model are made below.

\section{Age: stability/flexibility of the processing system}

Research indicates that the structural organisation of the mental lexicon is malleable and depends, among other factors, on experience. The more often a word is encountered, the easier it becomes to recognise. This phenomenon is captured in the frequency effect - calculated on the basis of text corpora, as an approximation of the experience with a word for the language user. There is evidence that regular verbs of high frequency are accessed via their stored full-forms rather than being computed (for English: Alegre \& Gordon, 1999; for 
Finnish: Lehtonen \& Laine, 2003; see also Lehtonen, Niska, Wande, Niemi, \& Laine, 2006; Soveri, Lehtonen, \& Laine, 2007; Stemberger \& MacWhinney, 1986).

Corpus-based frequency estimations serve as an approximation for experience in the language community, but not for individual experience. Language users accumulate encounters with inflected forms over the course of their lives, and older people have had more experience with particular word forms than younger people. Just like word frequency, experience, increasing with age, may influence the processing of inflected forms. The likelihood that inflected words, even regular ones, are recognised via storage may increase with age. This can either be the result of emerging full-form representations becoming more robust with exposure, or because the full-form access route becomes faster than the parsing route, as assumed in dual-route race models. Models that implement experience-dependent storage and computation would predict more full-form access and storage for the older participants.

\section{Frequency and number dominance in nouns}

As explained above, word frequency provides an important way to distinguish between processing models for inflected words. Word-form frequency plays a prominent role in full-listing and dual-route race models: frequent word forms are processed more quickly than infrequent ones, which in dual-route race models may have to proceed via the parsing route. To the extent that fulldecomposition models include a recombination stage at which the morphemes are recombined and checked for legality of their combination (to reject combinations such as *sheeps, see Taft, 2004), frequency may also impact reaction times (RTs) at this stage, with more frequent forms being easier to recombine. But to test fulldecomposition models as well as dual-system models with obligatory parsing of regular complex forms, it does not suffice to compare sets of words of high and low frequency. This is because the frequencies of inflectional variants of regular words have no impact on the speed with which the system decomposes complex forms into stem and affix, and may only affect later recombination stages. What matters for the parsing process is the frequency of the stem (also known as lemma frequency). Each encounter with a variant (e.g. plays, playing, played) adds to the frequency of the stem ("play"). What is needed are sets of words with identical lemma frequencies, but different inflectional-form frequencies. Ideally suited for this are singular (table) and plural (tables) forms of the same stem.
Baayen, Dijkstra, and Schreuder (1997) investigated how number dominance - that is, the (im-)balance between the form frequencies of the singular and the plural form of a word - influences the processing of Dutch plural nouns. Across the entire lexicon, singular forms are somewhat more frequent than plural forms (Baayen, Levelt, Schreuder, \& Ernestus, 2008), but there are numerous examples of plural-dominant words, denoting objects that typically occur in pairs or groups. For instance, while the word-form frequency is higher for bride than for brides (10 vs. 2 occurrences per million, as measured in CELEX, Baayen, Piepenbrock, \& Gulikers, 1995), peas is more frequent than pea (8 vs. 2 occurrences).

What do the models described above predict for the effects of number dominance? Under a full-listing account (Butterworth, 1983; Giraudo \& Grainger, 2000, 2001), all inflected forms are accessed via their individual word forms, which code for their frequencies. Frequent word forms should be processed and recognised more quickly than infrequent ones. Thus, a noun presented in its dominant (i.e. more frequent) number (peas, bride) will lead to faster reactions than the non-dominant/less frequent variant (pea, brides). This is the pattern illustrated in Figure 1(a). Connectionist models make similar predictions, since only full word forms play a role in the models. Note that epiphenomenal effects of stem frequency might show up in simulations, although stems do not exist as such in the models (see Davis, van Casteren, \& Marslen-Wilson, 2003).

Full-decomposition models (Taft, 2004; Taft \& Forster, 1975) assume that all inflected forms with detectable affixes are parsed. During this initial phase of lexical access, there is no room for the frequency of individual word forms, as only stem frequency plays a role (Bertram et al., 2000). The time that it takes to parse a singular-dominant compared to a plural-dominant noun should be the same, provided that their lemma frequencies are matched. It is only at the recombination stage that processing differences between plural forms of singular- and plural-dominant words may arise. Although their frequencies are not stored with complex forms, the recombination of stems and affixes may be easier/faster for frequent plurals (peas) than for infrequent ones (brides). In other words, within full-decomposition models, the amount of time spent at the recombination stage determines the expected RT pattern. Full decomposition with no (or a very short) recombination stage predicts longer RTs for peas and brides than for pea and bride (see Figure 1(b)). Full decomposition with a longer recombination stage predicts the pattern illustrated in Figure 1(c). Note that dual-route, dual-mechanism models (e.g. Clahsen, 1999; 
A: Full Listing

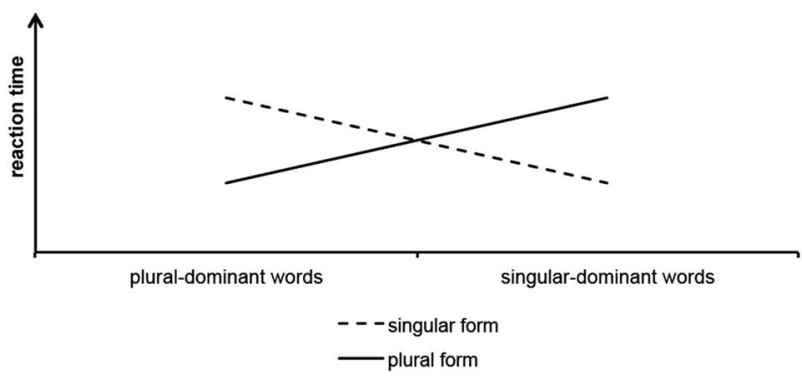

C: Full Decomposition with Recombination

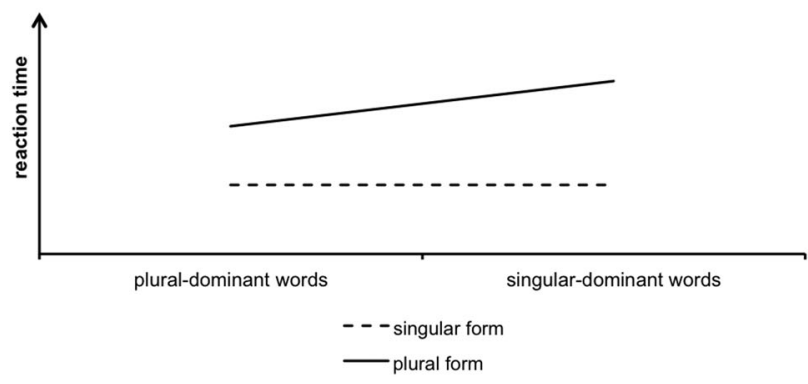

B: Full Decomposition without Recombination

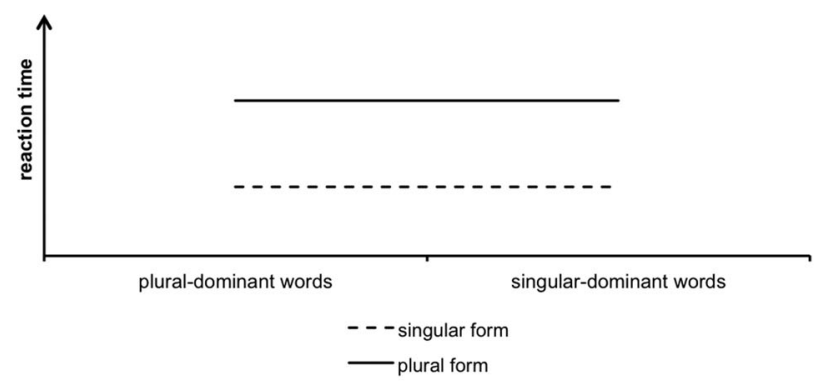

D: Parallel dual-route race model

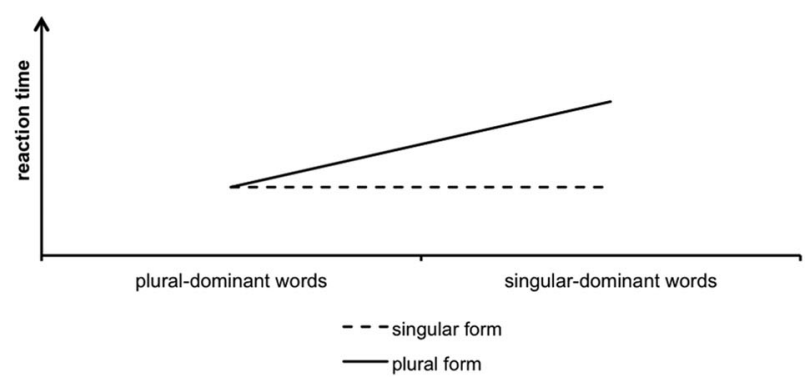

Figure 1. Reaction-time patterns predicted by different models of morphological processing. Source: Adapted from Baayen, Dijkstra, and Schreuder (1997).

Pinker, 1999) predict pattern B for regular or default plural forms, and pattern A for all other plurals.

Dual-route race models, in particular the one proposed by Schreuder and Baayen (1995), predict that the speed of recognising a singular form is determined by the summed frequency of the singular and plural forms. The recognition time for a plural form, however, is determined by its plural form frequency only. The logic goes as follows. Both singular and plural forms of a word are stored in the mental lexicon, and they are processed, in parallel, via direct access and via parsing. The route that is fastest wins. Whenever a plural form is encountered, this leads to a boost in activation for both the plural form itself (because it is directly activated) and the corresponding singular form contained in the input (through indirect activation feedback from the semantic/syntactic level). Importantly, only constituents contained in the original signal will benefit from this activation, leading to two caveats. First, only transparent plural forms lower the activation threshold of their singular form. Second, the activation relationship is asymmetric: encountering a singular form does not lead to an activation boost of the corresponding plural form because the plural form is not contained in the input. When a plural form is presented, both processes of the dual-route race model start in parallel. The decomposition route parses the word into its morphemes and looks up the stem, while the storage-based process searches for the full word form in the lexicon. Whichever process is faster will output the result. For singular-dominant forms, this leads to an effect of number; their singular forms (bride) are easy to recognise, but their plural forms (brides) need to be decomposed, which costs time. Plural-dominant words, however, should not exhibit an effect of number: their singular forms (pea) profit from the high frequency of their plural forms; and their plural forms are highly frequent and are recognised quickly via the access to their full form (peas, see Figure 1(d)).

Baayen, Dijkstra, and Schreuder (1997) examined effects of dominance (singular-dominant vs. plural-dominant) and number (singular form vs. plural form) on lexical-decision times for Dutch written words. They observed an interaction of dominance by number, very similar to Figure 1(d). This result was replicated for Dutch with auditory lexical decision (Baayen, McQueen, Dijkstra, \& Schreuder, 2003) and word production (Beyersmann, Dutton, Amer, Schiller, \& Biedermann, 2015), as well as for French (New et al., 2004), Spanish (Dominguez, Cuetos, \& Segui, 1999), and Italian (Baayen, Burani, \& Schreuder, 1997). This pattern fits with predictions by the dual-route race model (Schreuder \& Baayen, 1995), and is not easily reconciled with the other models presented above.

Because of its power to distinguish between models of plural processing, we used the written lexical-decision paradigm in the two experiments on number dominance reported below. Experiment 1 was carried out in German, 
and Experiment 2 in Dutch (see the Appendix). Assessing number dominance in German is particularly interesting because of its many affixes and ablauting for plural formation. If the data from our German participants replicate the interaction between dominance and number observed by Baayen, Dijkstra, and Schreuder (1997) for Dutch, this would speak for direct access and for decomposition. Dominance/frequency effects emanate from the full word forms, but note that the decomposition route is originally responsible for the asymmetry between plural and singular-dominant words. However, the morphological richness of German may induce parsing of all complex forms, without full-form storage, in which case we expect the pattern of Figure 1(b). A third option is direct access to stored forms for all plural forms, without parsing. This is a valid option given that the language has so many ways to instantiate plural on nouns. This would correspond to the pattern shown in Figure 1(a).

Moreover, we wanted to investigate the impact of experience of the language user with word forms, as a function of age, in both language groups. We thus tested two age groups of participants, with some 40 years of lifetime between the groups. Importantly, age functions as a proxy for exposure, and hence experience, here. If experience increases the likelihood of access to stored forms, either because full-form representations become more robust, or because the full-form access route becomes faster, we should observe different patterns for the younger and older participants. Specifically, there should be stronger evidence for storage of complex forms in older than in younger participants. In addition, we expected the older participants to show longer RTs than the younger ones due to age-related slowing (Salthouse, 1996, 2000; Verhaeghen \& Salthouse, 1997).

\section{Experiment 1: German}

\section{Method}

\section{Participants}

A younger and an older age group were tested in this experiment. The younger group consisted of 24 participants ( 22 female, no left-handed, $M_{\text {Age }}=21$, range Age $_{\text {e }}=$ 19-26), all students at Westfälische Wilhelms-Universität Münster. The older age group also consisted of 24 participants ( 17 female, no left-handed, $M_{\text {Age }}=66$, range ${ }_{\text {Age }}=$ 60-73), living in either Münster or Kranenburg. Participants reported having normal or corrected-to-normal vision and were either paid for their participation or received course credit. All participants provided informed consent to participate in the study, and all data were analysed anonymously.

\section{Materials}

The stimuli consisted of 540 German words and 540 pseudowords. The 270 singular and the corresponding 270 plural forms were split into eight groups according to plural type (four types) and singular or plural dominance. See Table 2 for an overview of the stimulus categories including information on lemma and form frequency for target items (all frequencies were logtransformed using the natural log). All experimental items were pretested with a group of 10 native speakers of German (none of whom participated in the experiment), who were given a list of singular words and were asked to write down the corresponding plural form. Only words that received $100 \%$ correct and unanimous responses were included in the experiment. For all plural types, form frequencies were significantly higher for the dominant type than for its non-dominant counterpart. Lemma ${ }^{2}$ frequency was constant within each plural type, and matched across plural types (Mannheim word frequency corpus, six million entries, as reported in CELEX, Baayen et al., 1995). The form frequencies of singular-dominant singular forms and plural-dominant plural forms did not significantly differ. Singular and plural forms had an average length of 4.95 letters and 6.06 letters, respectively. The items were rated for imageability on a 7-point-scale ( 1 = very abstract, $7=$ very imaginable) by 12 German native speakers (none of whom participated in the experiment). The average rating was 5.45 ( $S D=1.72$ ).

In total, 270 monomorphemic adjectives and adverbs were added as fillers.

The pseudowords were created by changing one phoneme/grapheme (usually the stressed vowel) of the experimental items. Illegal combinations of existing stems and existing affixes were avoided (see Taft, 2004, for a discussion of the influence of such pseudowords on morphological processing). Only one $\left({ }^{*} H u l d e\right)$ out of 540 pseudowords could potentially be interpreted as such an illegal combination.

The stimulus materials were distributed over two lists (A, B) of 1080 items each, with the same number of adjective fillers as there were test nouns. Half of the participants saw list $A$, the other half saw list $B$, so that each person saw either the singular or the plural form of each item.

\section{Apparatus}

The experiment was programmed using Presentation ${ }^{\circledR}$ (version 14.7, Neurobehavioral Systems, USA, 2004). The items were presented in black upper case (Arial font size 48) against a white background on a 17-inch iiyama HM703UT monitor. 
Table 2. Experiment 1, German: overview of the stimuli categories.

\begin{tabular}{|c|c|c|c|c|c|c|c|}
\hline \multirow[b]{3}{*}{ Type } & & & \multicolumn{3}{|c|}{ Frequency } & & \\
\hline & & & \multicolumn{2}{|c|}{ Form } & \multirow{2}{*}{ Lemma } & \multicolumn{2}{|c|}{$N$} \\
\hline & & & Singular & Plural & & Presented & Included \\
\hline \multicolumn{8}{|l|}{ Target items } \\
\hline & $-(e) n$ plurals & singular-dom. & 3.25 & 1.89 & 3.53 & 79 & 75 \\
\hline & & plural-dom. & 2.08 & 3.08 & 3.42 & 79 & 76 \\
\hline & -e plurals & singular-dom. & 4.50 & 2.62 & 4.82 & 27 & 24 \\
\hline & & plural-dom. & 3.06 & 3.99 & 4.62 & 27 & 23 \\
\hline & -er plurals & singular-dom. & 5.34 & 3.69 & 5.77 & 6 & 6 \\
\hline & & plural-dom. & 3.45 & 4.43 & 5.07 & 6 & 6 \\
\hline & -s plurals & singular-dom. & - & - & - & 6 & 0 \\
\hline & & plural-dom. & - & - & - & 6 & 0 \\
\hline & & & & & & (270) & $(210)$ \\
\hline Filler items & \multicolumn{5}{|c|}{ Adjectives, adverbs } & 270 & \\
\hline Pseudowords & \multirow{2}{*}{\multicolumn{5}{|c|}{ Phoneme-changed versions of target and filler items }} & 540 & \\
\hline Total & & & & & & 1080 & \\
\hline
\end{tabular}

Notes: Frequencies are log-transformed (natural log) and are computed over only those items included in the final analyses. The table also specifies how many items per category were included in the final analyses.

\section{Procedure}

Participants were tested individually, instructed by the experimenter and by standard instructions on the computer screen. There were 10 experimental blocks with 100 items each and a final block of 80 items. The first block was preceded by 10 practice trials. Participants were allowed to take short breaks after the practice block and between test blocks.

On every trial, first a fixation cross " + " appeared on the screen for $600 \mathrm{~ms}$, after which a test item appeared for a maximum of $2600 \mathrm{~ms}$. The experiment was quasi-selfpaced, as items disappeared as soon as a response was recorded. There was no feedback on accuracy.

\section{Results}

Forty-four of the 270 target items were excluded (in both singular and plural forms) because one or both forms received fewer than $50 \%$ correct reactions $(16.3 \%$ of the test items), presumably largely due to their low frequency. We also excluded all -s plurals from the analyses due to low accuracy rates for the majority of items and the somewhat unusual nature of most words (e.g. abbreviations, loanwords). The exclusion of these items did not affect the frequency matching for the remaining 210 items (see Table 2 for the values of included items).

The analyses of the RTs for the experimental items were based on correct responses only. Trials with RTs below 300 ms or more than 2.5 SDs above a participants' mean were excluded from the analyses (5.9\%).

We analysed the RT data in two ways. First, we present results of ANOVAs, following the original paper by Baayen, Dijkstra, and Schreuder (1997). This allowed for a direct comparison of our findings to their predictions and results. Second, the data were also analysed using linear mixed-effects models, allowing for the inclusion of
Lemma Frequency and Form Frequency as continuous, rather than dichotomous factors. We also re-coded Dominance as a continuous factor. The singular/plural frequency ratios are quite different for singular-dominant and pluraldominant words; singular forms of singular-dominant words are often many times more frequent than their plural form, while plural forms of plural-dominant words are usually only slightly more frequent than the corresponding singular forms (see Baayen et al., 2008, for a discussion on the dichotomisation of continuous factors as well as a reanalysis of the original data). Dominance was therefore used as a continuous factor (singular-form frequency divided by plural-form frequency), with values between 0 and 1 indicating plural dominance and values above 1 indicating singular dominance.

A preliminary analysis included plural type $(-e,-(e) n$, -er) as an independent within-subjects factor. The analysis yielded no significant main effect of this variable, or any interactions involving it. Furthermore, including plural type did not improve the fit of the model $\left(x^{2}(64)\right.$ $=75.058, p=.163)$. Thus, the analyses were performed across plural types.

\section{Analyses of variance}

ANOVAs with subjects and items as random factors revealed significant main effects of age $\left(F_{1}(1,46)=38.5\right.$, $\left.p<.001 ; \quad F_{2}(1,209)=104.1, \quad p<.001\right)$ and number $\left(F_{1}(1,46)=105.3, p<.001 ; F_{2}(1,209)=96.4, p<.001\right)$. As expected, older people had longer RTs than younger ones, and plural forms led to longer RTs than singular forms. Furthermore, there were a two-way interaction between number and dominance $\left(F_{1}(1,46)=25.2\right.$, $\left.p<.001 ; F_{2}(1,209)=19.7, p<.001\right)$ and a three-way interaction between age, dominance, and number $\left(F_{1}(1,46)\right.$ $\left.=10.6, p<.001 ; F_{2}(1,209)=5.2, p=.024\right)$. See Figure 2 for an illustration of the RT patterns. 


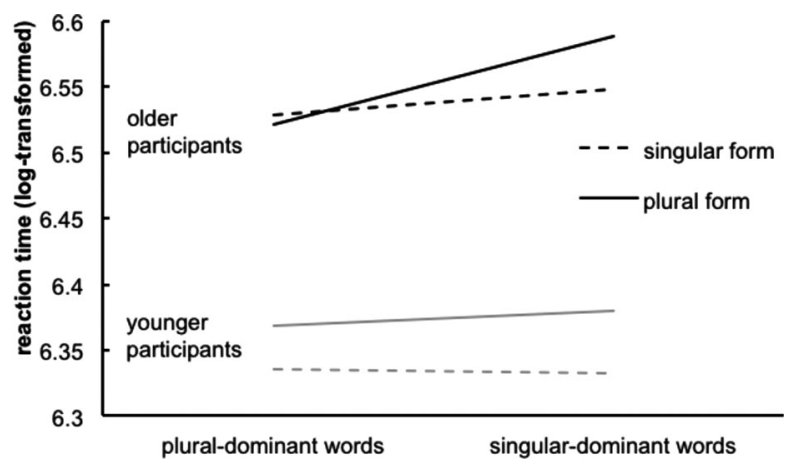

Figure 2. Experiment 1, German. RTs for younger and older German participants as a function of Dominance and Number.

To examine the nature of this interaction, separate analyses were carried out for the two groups of participants. For the younger participants, ANOVAs revealed a significant main effect of number $\left(F_{1}(1,23)=58.6, p\right.$ $\left.<.001 ; \quad F_{2}(1,209)=56.8, p<.001\right)$, with significantly longer RTs for plural than for singular forms. The interaction of number and dominance was significant only in the item analysis $\left(F_{2}(1,209)=5.4, p=.021\right)$, but not in the subject analysis $\left(F_{1}(1,23)=1.76, n s\right)$.

For the older participants, ANOVAs again revealed a significant main effect of number, with RTs being significantly longer for plural forms than for singular forms $\left(F_{1}(1,23)=51.4, p<.001 ; F_{2}(1,209)=60.2, p<.001\right)$. In contrast to the younger participants, older participants showed a significant interaction between number and dominance $\left(F_{1}(1,23)=32.8, p<.001 ; F_{2}(1,209)=18.7, p\right.$ $<.001)$. The effect of number was significant only for singular-dominant forms $(t=-2.26, p=.03)$, but not for plural-dominant forms $(t<1)$.

\section{Linear mixed-effects models}

Linear mixed-effects models were fitted on the log-transformed RTs (natural log), using the languageR package (Baayen, 2013) and the Ime4 package (Bates, Maechler, Bolker, \& Walker, 2014; R Development Core Team, 2008). Fixed factors were Number (singular/plural), Dominance (continuous), Lemma frequency (continuous), Form frequency (continuous), and Age (young/old), all of which were centred. Random factors were subjects and items. Following Barr, Levy, Scheepers, and Tily (2013), a series of models was created and random slopes were tested for inclusion against a by-subject and by-item random intercept model. The maximally converging model was selected. In cases of convergence failure, the model was simplified. Effects were considered significant at absolute $t$-values of 1.96 or above. See Table 3 for the overall model.

Number had a main effect on RTs $(t=-8.60)$; words were recognised more quickly when presented in their singular than in their plural form. Age also significantly affected RTs $(t=-6.50)$, with younger people responding more quickly than older people. There were significant main effects of lemma and form frequency, with higherfrequency items being recognised more quickly than lower-frequency items (lemma frequency: $t=-3.70$; form frequency: $t=-2.20)$. Lastly, there was a three-way interaction between age, dominance, and number ( $t=$ 2.00). For this reason, we split the data set by age group (see Tables 4 and 5 for details of the analyses).

The younger participants showed a main effect of number, favouring singular forms $(t=-5.96)$ and lemma frequency $(t=-2.92)$. Importantly, there was no

Table 3. Experiment 1, German: factors included in the model that best explains RTs.

\begin{tabular}{|c|c|c|c|c|c|}
\hline \multicolumn{3}{|c|}{ Fixed effects } & Estimate & Standard error & $t$-Value \\
\hline \multicolumn{3}{|l|}{ Intercept } & 6.460 & 0.020 & 415.40 \\
\hline \multicolumn{3}{|l|}{ age } & -0.200 & 0.030 & -6.50 \\
\hline \multicolumn{3}{|c|}{ dominance } & 0.008 & 0.010 & 0.80 \\
\hline \multicolumn{3}{|c|}{ number } & -0.040 & 0.005 & -8.60 \\
\hline \multicolumn{3}{|c|}{ form frequency } & -0.020 & 0.005 & -2.20 \\
\hline \multicolumn{3}{|c|}{ lemma frequency } & -0.020 & 0.005 & -3.70 \\
\hline \multicolumn{3}{|c|}{ age : dominance } & -0.006 & 0.010 & -0.60 \\
\hline \multicolumn{3}{|c|}{ age : number } & 0.005 & 0.008 & 0.70 \\
\hline \multicolumn{3}{|c|}{ dominance : number } & -0.020 & 0.013 & -1.50 \\
\hline \multicolumn{3}{|c|}{ age : form frequency } & -0.001 & 0.003 & -0.30 \\
\hline \multicolumn{3}{|c|}{ dominance : form frequency } & 0.002 & 0.006 & -0.40 \\
\hline \multicolumn{3}{|c|}{ number : form frequency } & 0.003 & 0.002 & 1.10 \\
\hline \multicolumn{3}{|c|}{ age : dominance : number } & 0.030 & 0.015 & 2.00 \\
\hline \multicolumn{3}{|c|}{ age : dominance : form frequency } & -0.001 & 0.006 & -0.04 \\
\hline \multicolumn{3}{|c|}{ age : number : form frequency } & -0.001 & 0.005 & -0.20 \\
\hline \multicolumn{3}{|c|}{ dominance : number : form frequency } & -0.001 & 0.004 & 0.01 \\
\hline \multicolumn{3}{|c|}{ age : dominance : number : form frequency } & -0.010 & 0.010 & -0.01 \\
\hline \multicolumn{2}{|c|}{ Random effects } & Variance & Standard deviation & $\mathrm{C}$ & \\
\hline \multirow[t]{2}{*}{ Items } & Intercept & 0.005 & 0.068 & & \\
\hline & age & 0.002 & 0.043 & -0.23 & \\
\hline \multirow[t]{3}{*}{ Subjects } & Intercept & 0.011 & 0.104 & & \\
\hline & number & 0.0001 & 0.011 & -0.99 & \\
\hline & dominance & 0.0001 & 0.011 & 0.00 & 0.00 \\
\hline \multicolumn{2}{|l|}{ Residual } & 0.028 & 0.167 & & \\
\hline
\end{tabular}


Table 4. Experiment 1, German: factors included in the model that best explains RTs of younger German speakers.

\begin{tabular}{|c|c|c|c|c|c|}
\hline \multicolumn{3}{|c|}{ Fixed effects } & Estimate & Standard error & $t$-Value \\
\hline & 6.36 & 0.02 & 297.48 \\
\hline \multicolumn{3}{|c|}{ dominance } & 0.004 & 0.01 & 0.36 \\
\hline \multicolumn{3}{|c|}{ number } & -0.04 & 0.01 & -5.96 \\
\hline \multicolumn{3}{|c|}{ form frequency } & -0.01 & 0.01 & -1.61 \\
\hline \multicolumn{3}{|c|}{ lemma frequency } & -0.02 & 0.01 & -2.92 \\
\hline \multicolumn{3}{|c|}{ dominance : number } & -0.01 & 0.02 & -0.38 \\
\hline \multicolumn{3}{|c|}{ dominance : form frequency } & -0.002 & 0.006 & -0.28 \\
\hline \multicolumn{3}{|c|}{ number : form frequency } & 0.002 & 0.003 & 0.67 \\
\hline \multicolumn{3}{|c|}{ dominance : number : form frequency } & -0.001 & 0.01 & -0.20 \\
\hline \multicolumn{2}{|c|}{ Random effects } & Variance & Standard deviation & \multicolumn{2}{|c|}{ Correlation } \\
\hline Items & Intercept & 0.004 & 0.066 & & \\
\hline \multirow[t]{3}{*}{ Subjects } & Intercept & 0.011 & 0.104 & & \\
\hline & number & 0.0002 & 0.013 & -1.00 & \\
\hline & dominance & 0.0003 & 0.012 & 0.26 & -0.20 \\
\hline Residual & & 0.026 & 0.162 & & \\
\hline
\end{tabular}

interaction between dominance and number $(t=-0.38)$. Thus, singular forms were recognised more quickly than plural forms, regardless of dominance. See Table 4 for the model.

The older participants also showed main effects of number, $(t=-7.03)$ and lemma frequency $(t=-2.84)$, and in addition a significant dominance-by-number interaction $(t=-2.01)$. While reactions to singular forms did not differ as a function of dominance, singular-dominant plural forms (e.g. brides) were associated with longer RTs than plural-dominant plural forms (e.g. peas). See Table 5 for the model.

For accuracy data, generalised linear mixed-effects models (binomial family) were calculated, using the language R package (Baayen, 2013) and the Ime4 package (Bates et al., 2014; R Development Core Team, 2008). We established the model that best explained accuracy rates on the basis of the independent factors of items (Dominance, Number) and subjects (Age). The fixed factors were centred. The overall rate of correct responses for included experimental items was $92.9 \%$. Table 6 provides an overview of the accuracy rates broken down by age group, dominance, and number.
There were significant main effects of age (greater accuracy for older people, $z=-6.50, p<.001$ ), number (greater accuracy for singular items, $z=2.25, p=.025$ ), and form frequency (greater accuracy for higher-frequency forms, $z=2.08, p=.038$ ). The three-way interaction between age group, dominance, and number was not significant $(z=-1.46, p=.144)$.

\section{Discussion}

Experiment 1 investigated how younger and older German speakers process written noun plurals in a lexical-decision task. With regard to accuracy rates, the numeric patterns for the two age groups differed from each other; however, statistical analyses of accuracy rates did not result in a three-way interaction, but only a main effect of number. While the focus of our discussion lies on the RT patterns, which were found to be statistically different for younger and older participants, the similarity in the numeric patterns of RT and accuracy is nevertheless noteworthy. This is particularly the case considering that Baayen, Dijkstra, and Schreuder (1997) also found a

Table 5. Experiment 1, German: factors included in the model that best explains RTs of older German speakers.

\begin{tabular}{|c|c|c|c|c|c|}
\hline \multicolumn{3}{|c|}{ Fixed effects } & Estimate & Standard error & $t$-Value \\
\hline \multirow{2}{*}{\multicolumn{3}{|c|}{$\begin{array}{l}\text { Intercept } \\
\text { dominance }\end{array}$}} & 6.56 & 0.02 & 301.74 \\
\hline & & & 0.01 & 0.01 & 0.92 \\
\hline \multicolumn{3}{|c|}{ number } & -0.05 & 0.01 & -7.03 \\
\hline \multicolumn{3}{|c|}{ form frequency } & -0.01 & 0.006 & -1.52 \\
\hline \multicolumn{3}{|c|}{ lemma frequency } & -0.02 & 0.01 & -2.84 \\
\hline \multicolumn{3}{|c|}{ dominance : number } & 0.04 & 0.02 & -2.01 \\
\hline \multicolumn{3}{|c|}{ dominance : form frequency } & -0.002 & 0.007 & -0.34 \\
\hline \multicolumn{3}{|c|}{ number : form frequency } & 0.003 & 0.003 & 1.02 \\
\hline \multicolumn{3}{|c|}{ dominance : number : form frequency } & -0.0004 & 0.007 & -0.05 \\
\hline \multicolumn{2}{|c|}{ Random effects } & Variance & Standard deviation & \multicolumn{2}{|c|}{ Correlation } \\
\hline Items & Intercept & 0.006 & 0.076 & & \\
\hline \multirow[t]{3}{*}{ Subjects } & Intercept & 0.011 & 0.105 & & \\
\hline & number & 0.0006 & 0.008 & -0.96 & \\
\hline & dominance & 0.00002 & 0.005 & -0.90 & 0.75 \\
\hline Residual & & 0.028 & 0.169 & & \\
\hline
\end{tabular}


Table 6. Experiment 1, German: accuracy rates broken down by age, number, and dominance.

\begin{tabular}{lcccc}
\hline & \multicolumn{2}{c}{ Younger group } & \multicolumn{2}{c}{ Older group } \\
\cline { 2 - 5 } & \multicolumn{4}{c}{ Presented number } \\
\cline { 2 - 5 } & Singular & Plural & Singular & Plural \\
\hline singular-dominant & $90.5 \%$ & $88.2 \%$ & $98.6 \%$ & $96.1 \%$ \\
plural-dominant & $89.2 \%$ & $86.9 \%$ & $96.0 \%$ & $96.9 \%$ \\
\hline
\end{tabular}

numeric similarity between their respective RT and accuracy patterns, although they did not report error analyses.

More interestingly, in the analyses of the RTs, we found both a main effect of age group as well as interactions with age group. Older speakers were slower to respond, which is to be expected given age-related slowing (Salthouse, 1996, 2000; Verhaeghen \& Salthouse, 1997). Their greater accuracy in the lexical decisions might thus be partly due to a speed-accuracy trade-off.

Furthermore, we also found that the two groups showed different effects of number dominance. The younger participants showed a main effect of number in both the ANOVA and linear mixed-effects models. RTs were longer for plural than for singular forms, regardless of number dominance. This pattern, shown in Figure 2 , corresponds to the pattern predicted by full-parsing models without a recombination stage (Figure 1(b)). It takes longer to process plural than singular forms because the parsing process required for plurals is time-consuming. There is no impact of the frequency of plural word forms: reactions to high-frequency forms such as peas take as long as reactions to low-frequency forms such as brides.

For the older participants, we found an interaction between dominance and number; there was a dominance effect for plural forms but not for singular forms. This is the pattern predicted by the dual-route race model (Figure $1(d)$ ). The account for this pattern according to the dual-route race model lies in the decomposition of noun plurals, which leads to a boost in activation of singular and plural forms. The singular forms of plural-dominant nouns (pea) profit from this; reactions to singular forms of singular-dominant nouns (bride) are as fast because they are frequent by themselves. The difference in RT between singular-dominant (brides) and plural-dominant (peas) plural forms is due to the fact that the direct access route wins for the latter as their plural forms are of high frequency.

In sum, we obtained different RT patterns for younger and older native speakers of German, with the older participants showing the interaction pattern reported by Baayen, Dijkstra, and Schreuder (1997) and Baayen et al. (2003) for a population of young Dutch students.
Before considering potential reasons for this difference, we report a parallel study carried out with speakers of Dutch. The aim was to determine whether young Dutch adults would still show the interaction reported by Baayen, Dijkstra, and Schreuder in 1997, and whether older Dutch adults would show the same or a different RT pattern.

\section{Experiment 2: Dutch}

\section{Method}

\section{Participants}

The younger age group consisted of 24 participants (20 female, 4 left-handed, $M_{\text {Age }}=21$, range $\left._{\text {Age }}=18-23\right)$, and so did the older age group (15 female, 1 left-handed, $M_{\text {Age }}=68$, range Age $=60-75$ ). All participants were recruited from the participant pool of the Max Planck Institute for Psycholinguistics, reported having normal or corrected-to-normal vision, and were paid for their participation. They provided informed consent to participate in the study, and all data were analysed anonymously.

\section{Materials}

The stimuli consisted of 216 existing Dutch words and 216 pseudowords, created by changing one phoneme of an existing word (usually a vowel). The target items were identical to those used by Baayen, Dijkstra, and Schreuder (1997). 93 singular nouns and their 93 plural forms were split into two sets according to their dominance (singular vs. plural). The sets were matched for lemma frequency, bigram frequency (based on the INL corpus, 42 million entries, CELEX; Baayen et al., 1995), and length. The average form frequency of singulardominant singular forms did not significantly differ from that of plural-dominant plural forms. Singular and plural forms had an average length of 4.28 letters and 6.28 letters, respectively. ${ }^{3}$ Twelve Dutch native speakers (none of whom had participated in the experiment) rated the items on a 7-point imageability scale $(1=$ very abstract, $7=$ very imaginable), with an average rating of $5.40(S D=1.85){ }^{4}$

Note that as in the original material set, only -en plural items were included in the analyses; some -s plural items were used as fillers along with adjectives and adverbs, with a total of 123 fillers. See Table 7 for an overview of the stimulus categories.

As in Experiment 1, pseudowords were created by changing one phoneme/grapheme of the experimental items. None of the pseudowords constituted an illegal combination of an existing stem and an existing affix (Taft, 2004). 
The stimuli were distributed over two lists of 432 items each, such that each list included one form of the experimental items (singular or plural) and all fillers and nonwords. Each list was seen by 12 younger and 12 older participants.

\section{Apparatus}

The same equipment was used as in Experiment 1.

\section{Procedure}

Participants were tested individually and received oral as well as standard instructions on the computer screen. There were four experimental blocks with 108 items each. The first experimental block was preceded by 10 practice trials. Participants were allowed to take short breaks after the practice block as well as between the four test blocks. Presentation details were identical to Experiment 1.

\section{Results}

Both forms of four items (boegen "bows" (front of a ship), loepen "magnifying glasses", ponten "ferryboats", stoeten "processions") were excluded from the analyses because one or both of their forms received fewer than $50 \%$ correct reactions. The exclusion of these items did not affect the frequency matching. Trials with RTs more than 2.5 SDs above the subject mean or shorter than $300 \mathrm{~ms}$ were discarded, as were trials with incorrect lexical decisions ( $11.5 \%$ in total).

As in Experiment 1, the RT data were analysed in two ways, with ANOVAs and linear mixed-effects models.

\section{Analyses of variance}

ANOVAs revealed significant main effects of age $\left(F_{1}(1,46)\right.$ $\left.=8.2, p<.001 ; F_{2}(1,87)=102.3, p<.001\right)$ and number $\left(F_{1}(1,46)=15.8, p<.001 ; F_{2}(1,87)=20.8, p<.001\right)$. Older people took longer to react, and plural forms led to longer RTs than singular forms. There was a two-way interaction between number and dominance $\left(F_{1}(1,46)=14.3\right.$, $\left.p<.001 ; F_{2}(1,87)=20.8, p<.001\right)$, showing that the effect of number was only significant for singular-dominant but not for plural-dominant forms. There was no three-way interaction between age, dominance, and

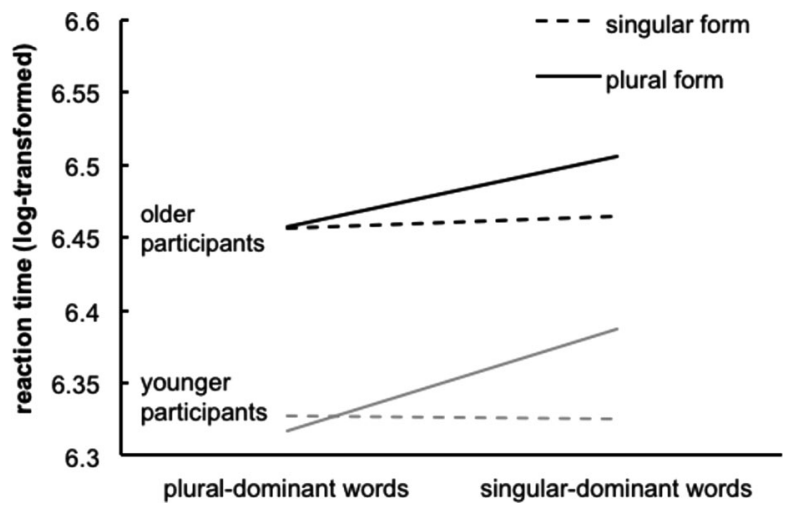

Figure 3. Experiment 2, Dutch. RTs for younger and older Dutch participants as a function of Dominance and Number.

number $\left(F_{1}(1,46)<1, n s ; F_{2}(1,87)=1.7, n s\right)$; that is, the dominance-by-number interaction held for both age groups (Figure 3).

\section{Linear mixed-effects models}

Linear mixed-effects models were fitted in the same manner as in Experiment 1. See Table 8 for the overall model. Dutch participants showed main effects of age (older people were slower than younger people; $t=$ -4.37), dominance (singular-dominant forms had longer RTs than plural-dominant forms; $t=2.88$ ), number (plural forms had longer RTs than singular forms; $t=2.04)$, form frequency $(t=-2.44)$, and lemma frequency $(t=-2.69)$.

Two interactions reached significance. An interaction between age and form frequency $(t=-4.98)$ was due to stronger form-frequency effects for older than for younger people. An interaction between dominance and number $(t=-3.51)$ revealed an effect of number for singular-dominant words, but not for plural-dominant words. Importantly, unlike for the Germans, there was no significant interaction between dominance, number, and age $(t=-0.90)$.

The analyses of the accuracy rates were analogous to Experiment 1. Table 9 shows the accuracy rates broken down by age group, dominance, and number.

As in Experiment 1, a significant main effect was found for age group, with greater accuracy for older

Table 7. Experiment 2, Dutch: overview of the stimuli categories.

\begin{tabular}{llcrrrr}
\hline & & \multicolumn{2}{c}{ Form frequency } & & \\
Type & & Singular & Plural & Lemma frequency & $N$ & Total \\
\hline Target items & & & & & \\
& Singular-dominant & 6.40 & 4.58 & 6.61 & 49 \\
& Plural-dominant & 5.14 & 6.03 & 6.43 & 44 \\
Filler items & Adjectives, adverbs, s-plural nouns & & & $93 \times 2$ \\
Pseudowords & Phoneme-changed versions of the target and filler items & & & 123 \\
Total & & & & \\
\hline
\end{tabular}


Table 8. Experiment 2, Dutch: factors included in the model that best explains RTs.

\begin{tabular}{|c|c|c|c|c|c|}
\hline \multicolumn{3}{|c|}{ Fixed effects } & Estimate & Standard error & $t$-Value \\
\hline \multicolumn{3}{|l|}{ Intercept } & 6.44 & 0.030 & 211.99 \\
\hline \multicolumn{3}{|c|}{ age } & -0.15 & 0.035 & -4.37 \\
\hline \multicolumn{3}{|c|}{ dominance } & 0.056 & 0.020 & 2.88 \\
\hline \multicolumn{3}{|c|}{ number } & 0.027 & 0.013 & 2.04 \\
\hline \multicolumn{3}{|c|}{ form frequency } & -0.001 & 0.006 & -2.44 \\
\hline \multicolumn{3}{|c|}{ lemma frequency } & -0.051 & 0.019 & -2.69 \\
\hline \multicolumn{3}{|c|}{ age : dominance } & 0.009 & 0.015 & 0.60 \\
\hline \multicolumn{3}{|c|}{ age : number } & 0.017 & 0.015 & 1.18 \\
\hline \multicolumn{3}{|c|}{ dominance : number } & -0.072 & 0.020 & -3.51 \\
\hline \multicolumn{3}{|c|}{ age : form frequency } & -0.020 & 0.004 & -4.98 \\
\hline \multicolumn{3}{|c|}{ dominance : form frequency } & -0.008 & 0.007 & -1.29 \\
\hline \multicolumn{3}{|c|}{ number : form frequency } & 0.003 & 0.003 & -0.82 \\
\hline \multicolumn{3}{|c|}{ age : dominance : number } & -0.018 & 0.020 & -0.90 \\
\hline \multicolumn{3}{|c|}{ age : dominance : form frequency } & -0.006 & 0.008 & -0.77 \\
\hline \multicolumn{3}{|c|}{ age : number : form frequency } & -0.006 & 0.006 & -0.92 \\
\hline \multicolumn{3}{|c|}{ dominance : number : form frequency } & -0.005 & 0.006 & -0.75 \\
\hline \multicolumn{3}{|c|}{ age : dominance : number : form frequency } & -0.017 & 0.012 & -1.40 \\
\hline \multicolumn{2}{|c|}{ Random effects } & Variance & Standard deviation & & \\
\hline \multirow[t]{2}{*}{ Items } & Intercept & 0.003 & 0.054 & & \\
\hline & age & 0.002 & 0.045 & 0.47 & \\
\hline \multirow[t]{3}{*}{ Subjects } & Intercept & 0.019 & 0.114 & & \\
\hline & number & 0.001 & 0.033 & -0.63 & \\
\hline & dominance & 0.0001 & 0.011 & 0.59 & -1.00 \\
\hline \multicolumn{2}{|l|}{ Residual } & 0.024 & 0.155 & & \\
\hline
\end{tabular}

people $(z=-5.05, p<.001)$. Number also affected accuracy rates, with higher accuracy for singular items $(z=$ $2.25, p=.025)$. The effect of form frequency approached significance ( $z=1.71, p=.088)$. Further, lemma frequency significantly influenced accuracy rates ( $z=2.68, p=.007)$. Again, the three-way interaction between age group, dominance, and number was not significant $(z<1, n s)$.

\section{Omnibus analysis: Experiment 1 and Experiment 2}

To test whether the numeric RT differences between the four groups of participants were statistically reliable, we combined the data sets from Experiments $1^{5}$ and 2 and fit an omnibus model with the fixed factors Dominance (continuous), Number (singular/plural), Age (young/old), Language (German/Dutch), Form Frequency (continuous), and Lemma Frequency (continuous) in the same manner as in the separate analyses for the two experiments. There were main effects of age (longer RTs for older speakers; $t=-6.15$ ), number (longer RTs for plural forms; $t=-7.57)$, form frequency $(t=-3.94)$, and lemma frequency $(t=-2.85)$. There was no main effect of language $(t=-1.10)$; however, an interaction between number and language indicated that the effect of number was greater in the German experiment

Table 9. Experiment 2, Dutch: accuracy rates broken down by age, number, and dominance.

\begin{tabular}{lcccc}
\hline & \multicolumn{2}{c}{ Younger group } & \multicolumn{2}{c}{ Older group } \\
\cline { 2 - 5 } & \multicolumn{4}{c}{ Presented number } \\
\cline { 2 - 5 } & Singular & Plural & Singular & Plural \\
\hline singular-dominant & $89.4 \%$ & $83.3 \%$ & $97.4 \%$ & $94.9 \%$ \\
plural-dominant & $88.8 \%$ & $90.8 \%$ & $97.0 \%$ & $96.7 \%$ \\
\hline
\end{tabular}

(Experiment 1) than in the Dutch experiment (Experiment 2). Importantly, there was a marginally significant four-way interaction between dominance, number, age, and language $(t=1.86)$.

A follow-up model containing only the young participants from both languages revealed significant a main effect of number (longer RTs for plural forms, $t=$ $-3.82)$, a main effect of form frequency $(t=-4.24)$, and, crucially, a significant three-way interaction between dominance, number, and language $(t=2.02)$.

\section{Discussion}

Using the same target materials as Baayen, Dijkstra, and Schreuder (1997), we replicated their findings. There was an effect of number for singular-dominant words, but not for plural-dominant words, indicating that the former (words like brides) are accessed via the decomposition route, while for the latter (words like peas), the fullform access route wins out. Older people took longer to react, but younger and older people showed very similar RT patterns, indicating that they processed the stimuli in a similar manner. These findings are in line with predictions made by the parallel dual-route race model (Schreuder \& Baayen, 1995) and replicate previous work on Dutch, Spanish, Italian, and French. As in Experiment 1 , the accuracy pattern looks very similar to the pattern for the RT data, but the interaction between number and dominance does not come out as significant. The same error pattern was also obtained by Baayen, Dijkstra, and Schreuder (1997), although the authors did not report statistical analyses on the error rates. 


\section{General discussion}

We investigated how younger and older German and Dutch adults process inflected plural forms of their language. These plural forms differed in surface frequency, as did their singular forms. When the plural form was dominant (as in peas), it was more frequent than its singular form (pea). When a singular form was dominant (as in bride), it was more frequent than its plural form (brides). The frequencies of the stems (lemma frequencies) were matched across the item sets. These materials are ideally suited to test the predictions of different models of morphological processing described in the Introduction, with their predictions visualised in Figure 1.

Younger and older adults were tested in both languages because age is a good proxy of experience with word forms. German and Dutch were chosen because the languages, though closely related, differ with respect to their inflectional richness, both for verbal and nominal inflection. In Dutch, plurals of nouns are generated by adding one of two suffixes; which one to use is largely predictable by phonology. This is different in German with its many ways to encode nouns for plural (see Table 1).

We surmised that such structural aspects of the language co-determine the processing of plural forms. As for the question which of the plural suffixes is regular, some believe that the -s plural is the default both in German and Dutch (Clahsen, 1999). Under this view, all plural forms used in the present experiments would be non-default or irregular as we did not analyse $-s$ plural forms. There is evidence for Dutch, that -en should be considered regular as well (Keuleers et al., 2007; Pinker, 1999; Van Wijk, 2002). -s and -en are in complimentary distribution and both are productive within their respective domain. An interesting finding from our experiments is that being the default form or regularity does not seem to be decisive for the way plural forms are processed, through parsing into morphemes or through whole-word access.

The data are clear-cut: all groups except younger Germans showed the same pattern of results. An omnibus model containing data from all four speaker groups revealed a marginally significant four-way interaction between Dominance, Number, Age, and Language, which suggests that the RT pattern for one of the four groups is different compared to the other three. In a follow-up model containing only data from the young participants from both languages we found a significant three-way interaction between Dominance, Number, and Language, which - especially in conjunction with a significant Dominance $\times$ Number $\times$ Age interaction for the German participants (Experiment 1) and the absence of such an interaction for the Dutch participants (Experiment 2) - indicates that it is the group of young Germans that shows a different RT pattern.

Before attempting to explain the odd-one-out pattern for young Germans, we explain the two result patterns by means of the predictions made by the models.

The data from the young German participants are consistent with the predictions made by full-parsing models. Plurals take longer to process than singulars - because the parsing routine takes time. There is no evidence for an impact of word-form frequency. This pattern would be in line with predictions made by dual-route, dualmechanism models (Clahsen, 1999; Pinker, 1999), except that it was obtained for plural affixes that are considered non-default or irregular. According to dual-mechanism models, such plurals should show the frequency effects depicted in Figure 1(a).

As laid out in the introduction, full-parsing models predict different patterns depending on the degree to which participants access a recombination stage at which they, for instance, check for illegal stem-affix combinations. It is at this stage that RTs might be impacted by the ease of recombining stems and affixes (see Figure 1(c); e.g. Taft, 2004). The pattern we observed for younger Germans seems at odds with an extensive effect of such a stage. What the younger Germans' data show instead is that they parse all plural forms of their language (which in our materials are all irregular) into stem and plural affix, seemingly without an additional recombination step before making the lexical decision (Figure 1(b)). Singular- and plural-dominant forms lead to similar response patterns as the main determinant of RTs is lemma frequency (for which the materials were matched). As parsing of complex forms takes time, plural forms take longer than singular forms.

The pattern shown by the three other groups neither fits full parsing (Figure 1(b)), nor full storage (Figure 1 (a)). Instead, it represents a mixture of storage and decomposition. This leaves two models: the decomposition-recombination model of Taft (2004), which allows for an impact of the ease of recombining stems and affixes (Figure 1(c)), and the dual-route race model of Baayen and colleagues (Baayen, Dijkstra, \& Schreuder, 1997; Schreuder \& Baayen, 1995), shown in Figure 1(d). The model of Taft predicts parsing costs for plural forms - depicted by the difference between easy-to-reassemble plurals (the dominant ones) and their non-inflected singular forms (Figure 1(c), left). None of the three groups shows such an effect of general parsing costs. It thus seems that the data fit best with the dual-route race model proposed by Baayen and colleagues. The pattern is explained by a combination of parsing and storage. 
Singular forms of singular-dominant words (bride) are of high frequency and recognised quickly by lexical lookup, but their plural forms (brides) need to be decomposed, which costs time. Plural-dominant words, however, show no such effect of number: their singular forms (pea) profit from the high frequency of their plural forms, their plural forms are highly frequent and are recognised quickly via the access to their full form (peas).

This leaves us with the riddle posed by young Germans: why do they parse all plural forms, while their Dutch age mates do not? We believe that the difference between these two groups reflects the morphological richness of German, in particular its rich inflectional paradigms. As the Dutch speakers have to deal with only two plural suffixes, the dual-route mechanism of parsing and full-form storage works well and in favour of the recognition of plural forms through a storage route, as long as they are frequent. This results in the interaction pattern shown by younger and older Dutch participants.

The younger Germans are confronted with a plethora of inflectional affixes, both for nouns and verbs, given case and agreement marking. This may well put them in parsing mode, which allows for the retrieval of semantic information - from the stem - and morpho-syntactic information carried by the affixes, relevant for syntactic processing. The language also has many plural affixes, and listeners seem to parse these as well. This is consistent with the economy of storage account (Frauenfelder \& Schreuder, 1992): a morphologically rich language has a large number of storable forms (which are in turn of comparatively low frequency), rendering whole-word access a less efficient processing method. It takes time, or rather experience, to reach the balance of processing via storage and parsing that is evident for Dutch. The older Germans seem to have reached this balance, by some 40 years of additional language exposure.

Despite the many similarities between Dutch and German, one may wonder whether differences between the two languages besides morphological complexity may have caused our two groups of young participants to behave differently. The stimuli used for the two languages - despite an "overlap" in 35 item sets were different. A first difference is that Dutch has a more consistent grapheme-phoneme mapping than German. Further, as pointed out in Table 1, several of the German plural types used in Experiment 1 have ablauting, which in the case of -e plurals is not predictable (Kuh/Kühe "cow(s)", Hund/Hunde "dog(s)"). In fact, almost $10 \%$ of the German items in Experiment 1 underwent vowel change, while this does not exist in Dutch. It is conceivable that such differences affect the way morphologically complex words are processed. A logical assumption is that a greater regularity leads to a larger degree of parsing, as irregularities need to be stored. However, this would predict that German participants should be more prone to storing these irregular forms. Yet, the pattern actually observed for young German participants is consistent with parsing rather than storage.

Another item-specific characteristic found to affect how language users process complex words is word length. Lemhöfer, Koester, and Schreuder (2011) investigated whether the phonotactic legality of letter combinations across the morpheme boundary influences the processing of compounds in Dutch, where compounds are most often spelled as single words without hyphenation. Native speakers' RTs and error rates were influenced by the presence of a phonotactic cue to a morpheme boundary when they had to process longer words (more than 10 letters), but not in shorter words. This suggests that word length affects morphological processing, with longer words being more likely to be parsed. German is notorious for the ease with which speakers concatenate stems, resulting in long compounds, whereas this is not so pervasive in Dutch. It is possible that the processing system of German speakers is more prone to parsing words, as this is a good strategy for long words. However, in the present study, the German plural forms were significantly shorter than the Dutch ones. Differences in the length of the actual stimuli are an unlikely basis for the different patterns we observed.

Another item-specific factor that may affect morphological processing is imageability. More imageable or concrete words are easier to store in, and access from, memory (Balota, Cortese, Sergent-Marshall, Spieler, \& Yap, 2004; Kounios \& Holcomb, 1994; Kroll \& Merves, 1986). Prado and Ullman (2009) introduced the notion of imageability as a diagnostic for storage when they observed imageability effects for stored irregular forms, but not for computed regular forms. One might ask whether our item sets differed with regard to imageability, which may have made some words more prone to be accessed from memory. However, there was no significant difference in imageability ratings of German compared to Dutch items. It is therefore unlikely that concreteness or imageability was a confounding factor between the two material sets.

In sum, while we cannot exclude the possibility that other differences between the experiments or the languages investigated may have impacted upon the results, differences between the languages in morphological complexity are most likely to be responsible for the differences in the patterns seen for young adults. This finding is of particular importance when considering that the vast majority of studies on morphological processing have been conducted on English. Our findings 
indicate that there may be systematic differences in the way native speakers of two closely related languages process inflected words.

To conclude, the present study investigated the influence of two factors - age of a speaker and morphological complexity of the language - on morphological processing by comparing younger and older speakers of German and Dutch. We found that German speakers' processing of morphologically complex words is affected by age. The pattern for older participants indicated parallel dual-route access with parsing for low-frequency forms and storage-based access for highly frequent forms, while younger participants seemed to decompose all forms regardless of frequency. We argue that greater age and, thus, greater experience with complex forms facilitates storage-based access of these forms.

By contrast, Dutch speakers of both age groups showed the same pattern as the older German participants - that is, parallel dual-route access employing both parsing and access from storage. We suspect that the different patterns found for the two languages are due to differences in morphological complexity, rendering parsing a more efficient process in German, which has many more inflectional variants. Our study provides evidence that written word processing is affected by both the morphological complexity of the language and the speakers' experience with the complex forms.

\section{Notes}

1. We did not use the $-\varnothing$ plural in the present study.

2. CELEX (Baayen et al., 1995) defines lemma frequency as the sum of the form frequencies of all inflections of a word of the same word class. That is, the lemma frequency for Lauf ("run", noun) is the added frequency of Lauf (singular form) and Läufe (plural form). Note that its lemma frequency does not include the form frequency for the verb forms lief (singular past tense), liefen (plural past tense), or gelaufen (past participle).

3. Dutch plural forms were significantly longer than German plural forms, $t(297)=2.66, p=.008$. See the General discussion section for further discussion of this difference.

4. There was no significant difference in imageability between German and Dutch items, $t_{1}(22)=0.28, n s$; $t_{2}(297)=0.46, n s$.

5. From Experiment 1, only -en plurals are included in this analysis to ensure maximal comparability to the data from Experiment 2 (which only includes Dutch -en plurals) in terms of number of items, presence of ablaut, and formal aspects of the affix.

\section{Acknowledgements}

We are grateful to Sophia Thrun and Stephanie Veldhuis for their assistance with testing the participants. We thank
Marcus Taft and one anonymous reviewer for helpful comments on earlier versions of this manuscript.

\section{Disclosure statement}

No potential conflict of interest was reported by the authors.

\section{Funding}

This research was supported by the Max-Planck-Gesellschaft zur Förderung der Wissenschaften, München, Germany.

\section{References}

Alegre, M., \& Gordon, P. (1999). Frequency effects and the representational status of regular inflections. Journal of Memory and Language, 40, 41-61. doi:10.1006/jmla.1998.2607

Andrews, S., \& Lo, S. (2013). Is morphological priming stronger for transparent than opaque words? It depends on individual differences in spelling and vocabulary. Journal of Memory and Language, 68, 279-296. doi:10.1016/j.jml.2012.12.001

Baayen, R. H. (2013). LanguageR: Data sets and functions with "analyzing linguistic data: A practical introduction to statistics". R package version 1.4.1.

Baayen, R. H., Burani, C., \& Schreuder, R. (1997). Effects of semantic markedness in the processing of regular nominal singulars and plurals in Italian. In G. E. Booij \& J. van Marle (Eds.), Yearbook of morphology 1996 (pp. 13-34). Dordrecht: Kluwer Academic.

Baayen, R. H., Dijkstra, T., \& Schreuder, R. (1997). Singulars and plurals in Dutch: Evidence for a parallel dual-route model. Journal of Memory and Language, 37, 94-117. doi:10.1006/ jmla.1997.2509

Baayen, R. H., Levelt, W. M. J., Schreuder, R., \& Ernestus, M. (2008). Paradigmatic structure in speech production. Proceedings of the Chicago Linguistics Society, 43, 1-28.

Baayen, R. H., McQueen, J., Dijkstra, T., \& Schreuder, R. (2003). Frequency effects in regular inflectional morphology: Revisiting Dutch plurals. In R. H. Baayen \& R. Schreuder (Eds.), Morphological structure in language processing (pp. 355-390). Berlin: Mouton de Gruyter.

Baayen, R. H., Piepenbrock, R., \& Gulikers, L. (1995). The CELEX lexical database. Linguistic data consortium. Philadelphia: University of Pennsylvania.

Baayen, R. H., Schreuder, R., de Jong, N., \& Krott, A. (2002). Dutch inflection: The rule that proves the exception. In $\mathrm{S}$. Nooteboom, F. Weerman, \& F. Wijnen (Eds.), Storage and computation in the language faculty (pp. 61-92). Dordrecht: Kluwer.

Balota, D. A., Cortese, M. J., Sergent-Marshall, S. D., Spieler, D. H., \& Yap, M. J. (2004). Visual word recognition of single-syllable words. Journal of Experimental Psychology: General, 133, 283316. doi:10.1037/0096-3445.133.2.283

Barr, D. J., Levy, R., Scheepers, C., \& Tily, H. J. (2013). Random effects structure for confirmatory hypothesis testing: Keep it maximal. Journal of Memory and Language, 68, 255-278. doi:10.1016/j.jml.2012.11.001

Bates, D., Maechler, M., Bolker, B., \& Walker, S. (2014). Ime4: Linear mixed-effects models using eigen and S4. R package version 1.1-7. 
Beretta, A., Campbell, C., Carr, T. H., Huang, J., Schmitt, L. M., Christianson, K., \& Cao, Y. (2003). An ER-fMRI investigation of morphological inflection in German reveals that the brain makes a distinction between regular and irregular forms. Lingua, 85, 67-92. doi:10.1016/S0093-934X(02)00560-6

Bertram, R., Laine, M., \& Karvinen, K. (1999). The interplay of word formation type, affixal homonymy, and productivity in lexical processing: Evidence from a morphologically rich language. Journal of Psycholinguistic Research, 28, 213-226. doi:10.1023/A:1023200313787

Bertram, R., Schreuder, R., \& Baayen, R. H. (2000). The balance of storage and computation in morphological processing: The role of word formation type, affixal homonymy and productivity. Journal of Experimental Psychology: Learning, Memory, and Cognition, 26, 489-511. doi:10.1037/02787393.26.2.489

Beyersmann, E., Dutton, E. M., Amer, S., Schiller, N. O., \& Biedermann, B. (2015). The production of singular- and pluraldominant nouns in Dutch. Language, Cognition and Neuroscience, 30, 867-876. doi:10.1080/23273798.2015.1027236

Brovetto, C., \& Ullman, M. T. (2005). The mental representation and processing of Spanish verbal morphology. In D. Eddington (Ed.), Selected proceedings of the 7th hispanic linguistics symposium (pp. 98-105). Somerville, MA: Cascadilla Proceedings Project.

Burani, C., \& Laudanna, A. (1992). Units of representation for derived words in the lexicon. Advances in Psychology, 94, 361-376. doi:10.1016/S0166-4115(08)62803-4

Butterworth, B. (1983). Lexical representation. In B. Butterworth (Ed.), Language production (Vol. 2, pp. 257-294). London: Academic Press.

Bybee, J. L. (1995). Regular morphology and the lexicon. Language and Cognitive Processes, 10, 425-455. doi:10. 1080/01690969508407111

Chialant, D., \& Caramazza, A. (1995). Where is morphology and how is it processed? The case of written word recognition. In L. B. Feldman (Ed.), Morphological aspects of language processing (pp. 55-78). Hillsdale, NJ: Erlbaum.

Clahsen, H. (1999). Lexical entries and rules of language: A multidisciplinary study of German inflection. Brain and Behavioral Sciences, 22, 991-1060. doi:10.1017/S0140525X99002228

Clahsen, H., Eisenbeiss, S., \& Sonnenstuhl-Henning, I. (1997). Morphological structure and the processing of inflected words. Theoretical Linguistics, 23, 201-249. doi:10.1515/thli. 1997.23.3.201

Clahsen, H., Marcus, G., \& Bartke, S. (1993). Compounding and inflection in German child language (Working Paper). Essex Research Reports in Linguistics, University of Essex, Colchester, UK.

Clahsen, H., Rothweiler, M., Woest, A., \& Marcus, G. F. (1992). Regular and irregular inflection in the acquisition of German noun plurals. Cognition, 45, 225-255. doi:10.1016/ 0010-0277(92)90018-D

Colé, P., Beauvillain, C., \& Segui, J. (1989). On the representation and processing of prefixed and suffixed derived words: A differential frequency effect. Journal of Memory and Language, 28, 1-13. doi:10.1016/0749-596X(89)90025-9

Cutler, A., Hawkins, J. A., \& Gilligan, G. (1985). The suffixing preference: A processing explanation. Linguistics, 23, 723-758. doi:10.1515/ling.1985.23.5.723

Davis, M. H., van Casteren, M., \& Marslen-Wilson, W. D. (2003). Frequency effects in processing inflected Dutch nouns: A distributed connectionist account. In R. H. Baayen \& R. Schreuder (Eds.), Morphological structure in language processing (pp. 427-462). Berlin: Mouton de Gruyter.

Dominguez, A., Cuetos, F., \& Segui, J. (1999). The processing of grammatical gender and number in Spanish. Journal of Psycholinguistic Research, 28, 485-498. doi:10.1023/ A:1023216326448

Feldman, L. B., \& Soltano, E. G. (1999). Morphological priming: The role of prime duration, semantic transparency, and affix position. Brain and Language, 68, 33-39. doi:10.1006/ brln.1999.2077

Frauenfelder, U. H., \& Schreuder, R. (1992). Constraining psycholinguistic models of morphological processing and representation: The role of productivity. In G. Booij \& J. van Marle (Eds.), Yearbook of morphology 1991 (pp. 165-183). Dordrecht: Kluwer.

Frost, R., Forster, K. I., \& Deutsch, A. (1997). What can we learn from the morphology of Hebrew? A masked-priming investigation of morphological representation. Journal of Experimental Psychology: Learning, Memory, and Cognition, 23, 829-856. doi:10.1037/0278-7393.23.4.829

Giraudo, H., \& Grainger, J. (2000). Effects of prime word frequency and cumulative root frequency in masked morphological priming. Language and Cognitive Processes, 15, 421444. doi:10.1080/01690960050119652

Giraudo, H., \& Grainger, J. (2001). Priming complex words: Evidence for supralexical representation of morphology. Psychonomic Bulletin \& Review, 8, 127-131. doi:10.3758/BF03196148

Keuleers, E., Sandra, D., Daelemans, W., Gillis, S., Durieux, G., \& Martens, E. (2007). Dutch plural inflection: The exception that proves the analogy. Cognitive Psychology, 54, 283-318. doi:10.1016/j.cogpsych.2006.07.002

Köpcke, K.-M. (1988). Schemas in German plural formation. Lingua, 74, 303-335. doi:10.1016/0024-3841(88)90064-2

Kounios, J., \& Holcomb, P. J. (1994). Concreteness effects in semantic processing: ERP evidence supporting dual-coding theory. Journal of Experimental Psychology: Learning, Memory, and Cognition, 20, 804-823. doi:10.1037/0278-7393.20.4.804

Kroll, J. F., \& Merves, J. S. (1986). Lexical access for concrete and abstract words. Journal of Experimental Psychology: Learning, Memory, and Cognition, 12, 92-107. doi:10.1037/0278-7393. 12.1.92

Laudanna, A., \& Burani, C. (1995). Distributional properties of derivational affixes: Implications for processing. In L. B. Feldman (Ed.), Morphological aspects of language processing (pp. 345-364). Hillsdale, NJ: Erlbaum.

Lehtonen, M., \& Laine, M. (2003). How word frequency affects morphological processing in monolinguals and bilinguals. Bilingualism: Language and Cognition, 6, 213-225. doi:10. 1017/S1366728903001147

Lehtonen, M., Niska, H., Wande, E., Niemi, J., \& Laine, M. (2006). Recognition of inflected words in a morphologically limited language: Frequency effects in monolinguals and bilinguals. Journal of Psycholinguistic Research, 35, 121-146. doi:10. 1007/s10936-005-9008-1

Lemhöfer, K., Koester, D., \& Schreuder, R. (2011). When bicycle pump is harder to read than bicycle bell: Effects of parsing cues in first and second language compound Reading. Psychonomic Bulletin \& Review, 18, 364-370. doi:10.3758/ s13423-010-0044-y

Lüttmann, H., Zwitserlood, P., \& Bölte, J. (2011). Sharing morphemes without sharing meaning: Production and 
comprehension of German verbs in the context of morphological relatives. Canadian Journal of Experimental Psychology/Revue Canadienne de Psychologie Expérimentale, 65, 173-191. doi:10.1037/a0023794

Marcus, G. F., Brinkmann, U., Clahsen, H., Wiese, R., \& Pinker, S. (1995). German inflection: The exception that proves the rule. Cognitive Psychology, 29, 189-256. doi:10.1006/cogp. 1995.1015

Marslen-Wilson, W. D., Tyler, L. K., Waksler, R., \& Older, L. (1994). Morphology and meaning in the English mental lexicon. Psychological Review, 101, 3-33. doi:10.1037/0033295X.101.1.3

Mugdan, J. (1977). Flexionsmorphologie und psycholinguistik. Tübingen: Narr.

Neurobehavioral Systems, USA. (2004). Presentation (Version 14.7) [Computer software]. Albany, CA: Neurobehavioral Systems. Retrieved from www.neurobs.com

New, B., Brysbaert, M., Segui, J., Ferrand, L., \& Rastle, K. (2004). The processing of singular and plural nouns in French and English. Journal of Memory and Language, 51, 568-585. doi:10.1016/j.jml.2004.06.010

Pinker, S. (1999). Words and rules: The ingredients of language. New York: HarperCollins.

Pinker, S., \& Ullman, M. T. (2002). The past and future of the past tense. Trends in Cognitive Sciences, 6, 456-463. doi:10.1016/ S1364-6613(02)01990-3

Plaut, D. C., \& Gonnerman, L. M. (2000). Are non-semantic morphological effects incompatible with a distributed connectionist approach to lexical processing? Language and Cognitive Processes, 15, 445-485. doi:10.1080/01690960050119661

Prado, E. L., \& Ullman, M. T. (2009). Can imageability help us draw the line between storage and composition? Journal of Experimental Psychology: Learning, Memory, and Cognition, 35, 849-866. doi:10.1037/a0015286

Prasada, S., \& Pinker, S. (1993). Generalisation of regular and irregular morphological patterns. Language and Cognitive Processes, 8, 1-56. doi:10.1080/01690969308406948

R Development Core Team. (2008). R: A language and environment for statistical computing. Vienna, Austria: $\mathrm{R}$ Foundation for Statistical Computing. ISBN 3-900051-07-0. Retrieved from http://www.R-project.org

Roelofs, A., \& Baayen, R. H. (2002). Morphology by itself in planning the production of spoken words. Psychonomic Bulletin and Review, 9, 132-138. doi:10.3758/BF03196269

Rueckl, J. G., Mikolinski, M., Raveh, M., Miner, C. S., \& Mars, F. (1997). Morphological priming, fragment completion, and connectionist networks. Journal of Memory and Language, 36, 382-405. doi:10.1006/jmla.1996.2489

Rumelhart, D. E., \& McClelland, J. L. (1986). On learning the past tenses of English verbs. In J. L. McClelland, D. E. Rumelhart, \& The PDP Research Group (Eds.), Parallel distributed processing: Explorations in the microstructure of cognition (Vol. 2, pp. 216271). Cambridge: MIT Press.

Salthouse, T. A. (1996). The processing-speed theory of adult age differences in cognition. Psychological Review, 103, 403-428. doi:10.1037/0033-295X.103.3.403

Salthouse, T. A. (2000). Aging and measures of processing speed. Biological Psychology, 54, 35-54. doi:10.1016/S03010511(00)00052-1
Schreuder, R., \& Baayen, R. H. (1995). Modeling morphological processing. In L. B. Feldman (Ed.), Morphological aspects of language processing (pp. 131-154). Hove: Erlbaum.

Seidenberg, M. S., \& Gonnerman, L. M. (2000). Explaining derivational morphology as the convergence of codes. Trends in Cognitive Sciences, 4, 353-361. doi:10.1016/S1364-6613(00) 01515-1

Smith, P. T. (1995). Are morphemes really necessary? In L. B. Feldman (Ed.), Morphological aspects of language processing (pp. 365-382). Hillsdale, NJ: Erlbaum.

Smolka, E., Zwitserlood, P., \& Rösler, F. (2007). Stem access in regular and irregular inflection: Evidence from German participles. Journal of Memory and Language, 57, 325-347. doi:10. 1016/j.jml.2007.04.005

Snow, C. E., Smith, N. S., \& Hoefnagel-Höhle, M. (1980). The acquisition of some Dutch morphological rules. Journal of Child Language, 7, 539-553. doi:10.1017/\$030500090000283X

Sonnenstuhl, E., Eisenbeiss, S., \& Clahsen, H. (1999). Morphological priming in the German mental lexicon. Cognition, 72, 203-236. doi:10.1016/S0010-0277(99)00033-5

Soveri, A., Lehtonen, M., \& Laine, M. (2007). Word frequency and morphological processing in Finnish revisited. The Mental Lexicon, 2, 359-385. doi:10.1075/ml.2.3.04sov

Stemberger, J. P., \& MacWhinney, B. (1986). Frequency and the lexical storage of regularly inflected forms. Memory \& Cognition, 14, 17-26. doi:10.3758/BF03209225

Taft, M. (1979). Recognition of affixed words and the word frequency effect. Memory \& Cognition, 7, 263-272. doi:10.3758/ BF03197599

Taft, M. (1994). Interactive-activation as a framework for understanding morphological processing. Language and Cognitive Processes, 9, 271-294. doi:10.1080/01690969408402120

Taft, M. (2004). Morphological decomposition and the reverse base frequency effect. The Quarterly Journal of Experimental Psychology Section A, 57, 745-765. doi:10.1080/ 02724980343000477

Taft, M., \& Forster, K. I. (1975). Lexical storage and retrieval of prefixed words. Journal of Verbal Learning and Verbal Behavior, 14, 638-647. doi:10.1016/S0022-5371(75)80051-X

Ullman, M. T. (2001). The declarative/procedural model of lexicon and grammar. Journal of Psycholinguistic Research, 30, 37-69. doi:10.1023/A:1005204207369

Van Wijk, J. (2002). The Dutch plural landscape. In H. Broekhuis \& P. Fikkert (Eds.), Linguistics in the Netherlands 2002 (pp. 211-221), Amsterdam: Benjamins.

Verhaeghen, P., \& Salthouse, T. A. (1997). Meta-analyses of agecognition relations in adulthood: Estimates of linear and nonlinear age effects and structural models. Psychological Bulletin, 122, 231-249. doi:10.1037/0033-2909.122.3.231

Veríssimo, J., \& Clahsen, H. (2009). Morphological priming by itself: A study of Portuguese conjugations. Cognition, 112, 187-194. doi:10.1016/j.cognition.2009.04.003

Westermann, G., \& Plunkett, K. (2007). Connectionist models of inflection processing. Lingue E Linguaggio, 6, 291-311. doi:10. $1418 / 25655$

Weyerts, H., Penke, M., Dohrn, U., Clahsen, H., \& Münte, T. F. (1997). Brain potentials indicate differences between regular and irregular German plurals. NeuroReport, 8, 957962. doi:10.1097/00001756-199703030-00028 